- always there. The complex handling of data and jobs between centres would be hidden from the end user by a new generation of software known as 'middleware'.

CERN's $\$ 1.8$ billion Large Hadron Collider (LHC) is an ideal test bed for the grid, as it will generate 7 petabytes $\left(10^{15}\right.$ bytes) of data every year when it comes online in 2005 . This information - requiring a thousand times more computing power than CERN can currently deliver - must be delivered to thousands of users in more than 40 countries. Using the grid concept, the Internet would function like a single computer and database rolled into one (see Nature 404, 213; 2000).

Political support for the programme is already high. Britain has pledged $£ 100$ million to grid computing. John Taylor, director general of the UK research councils, told research ministers in Lisbon last month that the grid represented a fundamental shift in computing, and would allow global teams of scientists to access large-scale computing resources and data collections distributed across many institutions and countries.

A $\$ 500$ million five-year grid effort is already under way in the United States, involving 50 research centres coordinated by the National Computational Science Alliance.

Preliminary discussions suggest that Europe's grid effort is likely to "match or exceed" that of the United States, says Robin Middleton, a scientist at the UK Rutherford Appleton Laboratory and the PPARC representative of the CERN proposal.

The CERN project is seen as a forerunner for similar proposals from other disciplines with similar computing needs, such as bioinformatics and astronomy.

\title{
Congo war increases threat to bonobo research
}

\section{Asako Saegusa, Tokyo}

Future research on the rarest and leastknown species of great ape is being seriously endangered by the intensifying civil war in the Democratic Republic of Congo, according to leading primate researchers.

They believe that threats to the wild population of bonobos (Pan paniscus), or pygmy chimpanzees, could jeopardize ongoing studies of their life histories and evolution. Work following up suggestions that bonobos might be useful in research on the origins of AIDS could also be harmed.

Wild bonobos are found only in Congo. Their population was estimated at around 10,000 in 1996, but is thought to have halved over the past few years as a result of habitat loss and an increase in hunting for their meat. The recent outbreak of armed conflict within core bonobo habitats is believed to have reduced their numbers still further.

"Ongoing [great ape] conservation programmes are subject to severe disruption all too often," says Richard Wrangham, a Harvard University primatologist. He notes that more than two-thirds of 23 protected areas containing great apes have been disturbed by military conflicts during the past ten years.

"Since bonobos were the last of the great apes to be studied, their life history is yet to be understood," says Takayoshi Kano, a primate researcher at Kyoto University, who launched a pioneering study on wild bono-

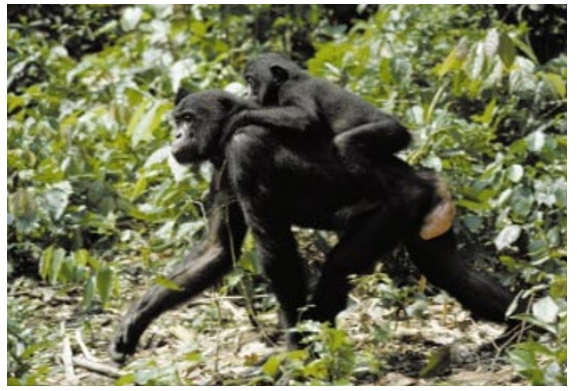

Bonobos: endangered on more than one front.

bos in 1973. "Even if bonobos do survive the ravages of war, their population will have been disrupted, and beginning a fresh study on a different group would be an unthinkably daunting task."

As human contact with bonobos increases with accelerated hunting - which often involves primitive butchery - there is growing concern over the risks that the apes could transmit disease to humans. Particularly in the light of the recent discovery that primate retroviruses can be transmitted to humans relatively easily through hunting.

Recent findings that HIV-1 might have arisen from chimpanzees in central Africa have triggered interest in bonobos as a research subject, although SIV - the ape equivalent of HIV - has not been detected from the handful of bonobo samples that have been tested so far.

\section{$\mathrm{NIH}$ takes charge of chimps infected in experiments}

\section{Paul Smaglik, Washington}

The US National Institutes of Health (NIH) has taken over responsibility for $\mathbf{2 8 8}$ chimpanzees infected with HIV and hepatitis $\mathrm{C}$ as a result of research projects. The chimps are currently housed at the Coulston Foundation in Alamogordo, New Mexico.

Coulston, a private research laboratory, has been criticized by animal-rights groups for the conditions under which its animals are kept, and has been chastised by the US Department of Agriculture (USDA). But it is still in the running to bid for contracts to care for the animals.

Coulston, which was founded by Frederick Coulston, lost two such contracts last year after USDA investigations ruled that the facility had violated the Animal Welfare Act. USDA inspectors reported that Coulston's chimp housing was dirty, infested and poorly ventilated. According to

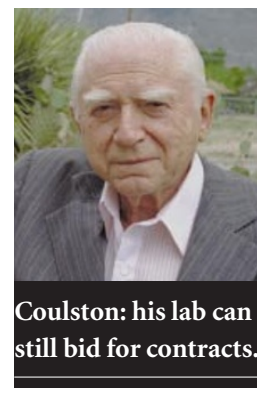

the department, these conditions contributed to the deaths of three chimps.

The loss of the contracts - worth $\$ 10$ million over six years - put the Coulston lab in financial trouble and cast doubts over its

future (see Nature 398, 644; 1999). Its financial situation "has become very critical", says John Strandberg, NIH director of comparative medicine.

But a successful bid by Coulston could help keep the organization solvent. Bids will begin in June and will undergo peer review. Don McKinney, a spokesman for Coulston, declines to comment on whether it will bid for the contract. However, he says he is "enthused" that NIH is supporting care of the animals.

Most of the 288 chimps, which represent about half of Coulston's total chimp population, are housed at Alamogordo's Holloman Air Force Base, leased by Coulston. Of the 288,25 remain in active clinical trials. The foundation will still own around 300 other chimps.

Strandberg says Coulston deserves to bid for the chimps' care, since conditions there have improved. "They have been intensively monitored," Strandberg says. "They've responded to many of the issues."

The California group In Defense of Animals, which opposes animal research, disagrees. It wants the permanent retirement of all chimpanzees used in government-sponsored research and opposes any involvement in their care by Coulston. “The NIH's deal does not accomplish either of these pressing goals," says Elliot Katz, the group's president. 